\title{
The impact of feedback semantics in visual word recognition: Number-of-features effects in lexical decision and naming tasks
}

\author{
PENNY M. PEXMAN \\ University of Calgary, Calgary, Alberta, Canada \\ STEPHEN J. LUPKER \\ University of Western Ontario, London, Ontario, Canada \\ and \\ YASUSHI HINO \\ Chukyo University, Nagoya, Japan
}

\begin{abstract}
The notion of feedback activation from semantics to both orthography and phonology has recently been used to explain a number of semantic effects in visual word recognition, including polysemy effects (Hino \& Lupker, 1996; Pexman \& Lupker, 1999) and synonym effects (Pecher, 2001). In the present research, we tested an account based on feedback activation by investigating a new semantic variable: number of features (NOF). Words with high NOF (e.g., LION) should activate richer semantic representations than do words with low NOF (e.g., LIME). As a result, the feedback activation from semantics to orthographic and phonological representations should be greater for high-NOF words, which should produce superior lexical decision task (LDT) and naming task performance. The predicted facilitory NOF effects were observed in both LDT and naming.
\end{abstract}

Although the average speaker or reader of English seldom notices it, the English language is actually quite ambiguous in its usage. For example, many English words are polysemous, in that they have multiple meanings (e.g., BANK). Thus, understanding the intended meaning requires the use of context. These polysemous words have been a useful tool in psycholinguistic research, since they allow researchers the opportunity to study the impact of semantic ambiguity on word recognition and reading.

There is now considerable evidence that semantic ambiguity produces a processing advantage in lexical decision tasks (LDTs) and naming tasks. That is, responding in those tasks is usually faster to polysemous words than to nonpolysemous words (Borowsky \& Masson, 1996; Gottlob, Goldinger, Stone, \& Van Orden, 1999; Hino \& Lupker, 1996; Hino, Lupker, Sears, \& Ogawa, 1998; Jastrzembski, 1981; Jastrzembski \& Stanners, 1975; Kellas, Ferraro, \& Simpson, 1988; Lichacz, Herdman, LeFevre, \& Baird,

\footnotetext{
This research was supported in part by grants to P.M.P. and S.J.L. from the Natural Sciences and Engineering Research Council (NSERC) of Canada. The authors thank Ken McRae for providing us with the feature norms, Lorraine Reggin and Jodi Edwards for programming the experiments and testing the participants, Martha Roberts for pointing out that NOF and frequency were confounded for our stimuli, and Derek Besner and Ron Borowsky for their comments on earlier drafts of the paper. Correspondence concerning this article should be addressed to P. M. Pexman, Department of Psychology, University of Calgary, 2500 University Drive NW, Calgary, AB, T2N 1N4 Canada (e-mail: pexman@ucalgary.ca).
}

1999; Millis \& Button, 1989; Pexman \& Lupker, 1999; Rubenstein, Garfield, \& Millikan, 1970). This effect has proven difficult to explain for current models of word recognition. For example, Joordens and Besner (1994) attempted to simulate polysemy effects, using two PDP models, but found that neither model was successful. The problem is that polysemy involves a one-to-many mapping between orthography and semantics and, thus, polysemous words should create competition in the semantic units. Because Joordens and Besner assumed that lexical decision performance depends on the settling time in the semantic units, the inevitable result was that this competition hindered, rather than facilitated, performance. That is, according to this and similar models, polysemy should produce a processing disadvantage in LDTs (for related discussions, see Besner \& Joordens, 1995; Borowsky \& Masson, 1996; Kawamoto, Farrar, \& Kello, 1994; Piercey \& Joordens, 2000; Rueckl, 1995).

As Hino and Lupker (1996) argued, however, it is possible to explain polysemy effects within a PDP framework if slightly different assumptions are made. Following Balota, Ferraro, and Connor's (1991) basic argument (see also Besner \& Smith, 1992; Borowsky \& Besner, 1993; Stolz \& Neely, 1995), Hino and Lupker suggested that polysemy effects were due to the impact of feedback activation from semantic units to orthographic units. That is, when a target word is presented, there is initially activation of an orthographic representation for that word. Very quickly, there is also activation of a semantic rep- 
resentation for the target word (and also activation of its phonological representation). The semantic representation then increases the activation of the orthographic (and phonological) representation via feedback connections. Because polysemous words (e.g., BANK) have a more extensive semantic representation than do nonpolysemous words, polysemous words will produce more semantic activation than do nonpolysemous words. Hence, the feedback activation from semantics to orthography should be stronger for polysemous words than for nonpolysemous words. As a result, the activation in the orthographic units for polysemous words should increase more rapidly than that for nonpolysemous words. Assuming that lexical decision responses are mainly based on orthographic activation, the expectation is that LDT responses should be faster for polysemous than for nonpolysemous words, as is typically observed.

The explanation for polysemy effects in naming tasks is similar. The many-to-one mappings from semantics to phonology for polysemous words should lead to a more rapid accumulation of activation at the phonologicallevel for those words (either through feedforward connections for orthographic-semantic-phonological linkages or through feedback connections for orthographic-phonologicalsemantic-phonological linkages). Assuming that naming responses are based on activation in the phonological units, polysemous words should, therefore, produce faster naming responses than do nonpolysemous words, just as Hino and Lupker (1996) observed. Thus, according to Hino and Lupker, polysemy effects in both tasks can be readily explained within a fully interactive, PDPtype model of word recognition if feedback activation is assumed to play an important role in the process.

Note that certain models of word recognition do assume an important role for feedback connections. For example, Van Orden and Goldinger (1994; see also Stone, Vanhoy, $\&$ Van Orden, 1997) argued for a system that incorporated both feedforward and feedback activation between sets of processing units. In addition, in Seidenberg and McClelland's (1989) PDP model, feedback connections were proposed but were never implemented. Feedback connections from semantic to orthographic units were also included in some of Plaut and Shallice's (1993) simulations. Thus, models of this sort would be quite consistent with the existence of polysemy effects.

Polysemy effects are not the only effects in the word recognition literature consistent with Hino and Lupker's (1996) feedback activation account. For example, Pexman, Lupker, and Jared (2001) argued that a feedback activation explanation, involving feedback from the phonological to the orthographic units, was required in order to explain homophone effects. Homophones are words like MAID and MADE, for which multiple spellings (and meanings) correspond to a single phonological representation. As had been typically reported (e.g., Rubenstein, Lewis, \& Rubenstein, 1971), homophones produced longer lexical decision response latencies than did control words in Pexman et al.'s experiments. These homophone effects were most apparent for low-frequency homophones with high-frequency homophone mates and were larger in LDTs when pseudohomophones (e.g., BRANE) were used as foils (as compared with pseudoword foils; e.g., PRANE).

Pexman et al. (2001) suggested that when a homophone target is presented (e.g., MAID), there is initially activation of an orthographic representation for the target word, which very quickly activates (via feedforward connections) the target's phonological representation (e.g., $/ \mathrm{mejd} /$ ). Via feedback connections, the phonologicalrepresentation then sends activation to the orthographic representation for the target word and, most important, also to the orthographic representation for the homophone mate (e.g., MADE). The result is competition between these two orthographic representations, which delays responding for a homophone target. When pseudohomophone foils are used, the LDT becomes more difficult, and response times are slower (e.g., Gibbs \& Van Orden, 1998; Stone \& Van Orden, 1993). Pexman et al. suggested that, in a difficult LDT, participants adopt a higher criterion for orthographic activation in order to distinguish the foils from words. This prolongs responding, and hence, there is more opportunity for feedback activation to influence responses.

In terms of the feedback activation account, homophone effects are attributed to a single phonological representation's activating two orthographic representations (Pexman et al., 2001) whereas polysemy effects are attributed to multiple semantic representations' activating a single orthographic representation (Hino \& Lupker, 1996). That is, despite the fact that these two effects go in opposite directions, they are both presumed to be due to the basic architecture of the word recognition system (rather than being due to specific strategies). Pexman and Lupker (1999) argued that if this account is correct, the two effects should occur simultaneously (i.e., in the same trial block), and both effects should be larger whenever there is increased opportunity for feedback to affect processing (i.e., with pseudohomophone foils). As was predicted, Pexman and Lupker found that polysemy and homophone effects cooccurred and that both were significantly larger with pseudohomophone foils than with pseudoword foils, supporting the feedback activation account.

One additional result that is consistent with Hino and Lupker's (1996) account comes from Pecher's (2001) examination of a different semantic variable: number of synonyms. As was noted above, homophones involve a oneto-many feedback mapping from the phonological units to the orthographic units. Similarly, words with synonyms involve a one-to-many feedback mapping from the semantic units to the orthographic units. Thus, the feedback activation for a word with synonyms would tend to be dispersed to different orthographic representations, which should produce competition at the orthographic level. As a result, words with synonyms should be at a processing disadvantage. Indeed, Pecher reported that responses were slower for words with synonyms (e.g., JAIL) than for words without synonyms (e.g., MILK) in both LDTs and naming tasks (see also Hino, Lupker, \& Pexman, 2002). 
The purpose of the present paper was to provide a new examination of the feedback activation account. Polysemous words, such as BANK, have a number of different, relatively distinct meanings. Thus, according to the feedback activation account, these words create considerable semantic activation and, hence, more feedback activation for their orthographic and phonological units, producing faster responding. A similar result should obtain whenever one type of word creates relatively more semantic activation than does another type of word, even if that enhanced activation is not due to those words' having different numbers of distinct meanings. In order to examine this prediction, we investigated the effect of number of features (NOF) in LDTs and naming tasks.

Semantic features are attributes or characteristics that describe the meaning of a word. For instance, for the word LAMP, its semantic features might include such things as is bright, has light bulbs, produces heat, has a shade, and so on. The notion that word meanings can be represented by semantic features has been controversial (e.g., Keil, 1989; Medin, 1989; Rips, 1989). That is, concept representations seem to involve much more than feature information, including such things as general world knowledge about relations between features and heuristics like essentialism (the notion that things like lamps have "essences"). McRae, de Sa, and Seidenberg (1997; see also McRae, Cree, Westmacott, \& de Sa, 1999) suggested, however, that featural representations play an important role in at least the initial computation of word meaning. On the basis of the feedback activation account, it would be predicted that words with many features would produce more semantic activation and, hence, more feedback to the orthographic and phonological units than do words with few features. Thus, in LDTs and naming tasks, faster responding should be observed for words with a large number of features than for words with a small number of features.

The suggestion that word recognition may be faster for words with more semantic activation, or richer semantic representations, is not a new one. In previous research, effects of concreteness and/or imageability have been examined (e.g., Cortese, Simpson, \& Woolsey, 1997; de Groot, 1989; James, 1975; Strain \& Herdman, 1999; Strain, Patterson, \& Seidenberg, 1995; Zevin \& Balota, 2000), with results tending to show faster responding in LDTs and naming tasks for concrete or imageable words than for abstract or nonimageable words. It has been argued, in fact, that highly imageable or concrete words have richer semantic representations because they activate more semantic features than do abstract words (Jones, 1985; Plaut \& Shallice, 1993). According to the feedback activation account, however, activation of a larger number of semantic features should facilitate word recognition even when all of the stimuli are highly imageable or concrete. Thus, there should be NOF effects when concreteness has been controlled.

In the present research, we tested this prediction. Experiments 1A and 1B were both LDTs; we used pseudo- word foils in 1A and pseudohomophone foils in 1B. Experiment $1 \mathrm{C}$ was a naming task. The prediction derived from the feedback activation account was that LDT and naming performance should be facilitated for high-NOF words. We should note that the feedback account is not the only possible explanation for NOF effects in LDTs and naming tasks. For instance, NOF effects in LDTs could perhaps be explained by semantic activation alone if one characterized LDT performance in terms of semantic level monitoring (e.g., Borowsky \& Besner, 1993). NOF effects in naming could perhaps be described as feedforward effects if one attributed these effects only to activation along the orthography-semantics-phonology pathway. The feedback activation account, however, seems to provide a parsimonious explanation for many word recognitionfindings, and in the present research, we provide an additional empirical test of that account.

\section{METHOD}

\section{Participants}

The participants in these experiments were undergraduate students at the University of Calgary, who received bonus credit in a psychology course in exchange for their participation. There were 40 participants in Experiment 1A, 38 in Experiment 1B, and 35 in Experiment 1C. All the participants had normal or corrected-tonormal vision and considered English to be their first language.

\section{Stimuli}

Words. In order to select the word stimuli for Experiments 1A, $1 \mathrm{~B}$, and $1 \mathrm{C}$, we chose 88 potential words from norms provided by Ken McRae (see McRae \& Cree, in press). Note that the McRae norms were empirically derived: A large number of participants were asked to list features for a set of concepts. Of the 88 words chosen, all were concrete, 44 were the words with the highest NOF, and 44 were the words with the lowest NOF. We asked 33 participants (who did not participate in Experiments 1A, 1B, or 1C) to rate the words for number of meanings and subjective familiarity. We then selected those words that were rated as having essentially only one meaning and, from them, created two sets: One set consisted of 25 words with low NOF, and the other set consisted of 25 words with high NOF. ${ }^{1}$ These sets were matched as closely as possible on several dimensions (see Table 1).

Foils. There were 60 pseudowords presented in Experiment $1 \mathrm{~A}$ and 60 pseudohomophones presented in Experiment 1B. These foils were used in Pexman et al. (2001; Experiment 1) and were pilot-tested extensively to ensure that the participants would recognize that each of the pseudohomophones would sound like a real word if pronounced, whereas the pseudowords would not. These foils were also matched orthographically so that each pseudoword (e.g., MEAP) shared its body with a pseudohomophone (e.g., KEAP).

\section{Procedure}

On each trial, a letter string was presented in the center of a 17-in. Sony Trinitron monitor controlled by a MacIntosh G3 and was presented using PsyScope (Cohen, MacWhinney, Flatt, \& Provost, 1993). Letters were approximately $0.50 \mathrm{~cm}$ high, viewed from a distance of approximately $40 \mathrm{~cm}$. In Experiments $1 \mathrm{~A}$ and 1B, lexical decision responses were made by pressing either the left button (labeled NONWORD) or the right button (labeled WORD) on a PsyScope response box. In Experiment $1 \mathrm{C}$, naming responses were made into a microphone attached to a PsyScope response box.

The participants first completed 12 practice trials with verbal feedback about incorrect responses. On each trial, the target was 
Table 1

Mean Characteristics (with Standard Deviations) for Word Stimuli as a Function of Number-of-Features (NOF) Condition

\begin{tabular}{|c|c|c|c|c|}
\hline \multirow[b]{2}{*}{ Word Characteristic } & \multicolumn{2}{|c|}{ Low-NOF Words } & \multicolumn{2}{|c|}{ High-NOF Words } \\
\hline & $M$ & $S D$ & $M$ & $S D$ \\
\hline Number of features & 12.00 & 1.50 & 20.40 & 1.78 \\
\hline Kučera and Francis (1967) frequency & 10.80 & 15.97 & 14.32 & 8.24 \\
\hline Subjective familiarity & 3.84 & 1.12 & 3.97 & 1.47 \\
\hline Number of meanings & 1.08 & 0.07 & 1.07 & 0.09 \\
\hline Word length & 6.28 & 1.67 & 5.52 & 1.58 \\
\hline Number of syllables & 1.80 & 0.71 & 1.56 & 0.65 \\
\hline Orthographic neighborhood size & 3.00 & 3.19 & 3.64 & 4.32 \\
\hline
\end{tabular}

presented until the participant responded. The intertrial interval was $1,500 \mathrm{msec}$. The stimuli were presented in a different random order for each participant.

\section{RESULTS AND DISCUSSION}

\section{Experiment 1A}

In this experiment, a trial was considered an error and was excluded from the latency analysis if the response time was longer than $2,000 \mathrm{msec}$ or shorter than $250 \mathrm{msec}$ (fewer than $1 \%$ of the trials) or if the participants made an incorrect response (4.0\% of the trials). For word responses, mean latencies and mean error percentages are presented in Table 2. For nonword responses, the mean latency was $602 \mathrm{msec}$, and the mean error percentage was $4.0 \%$.

In selecting stimuli for these experiments, we attempted to control word frequency, subjective familiarity, word length, orthographic neighborhood size $(N)$, number of syllables, and number of meanings. It is evident from the means provided in Table 1, however, that there were small differences in the mean values of these characteristics for our low- and high-NOF words. The low-NOF words were somewhat less frequent and less familiar and tended to be longer and have more syllables than did the high-NOF words. In order to test for unique effects of NOF, independent of these other factors, we conducted stepwise multiple regression analyses using item means. First, we examined correlations among these characteristics for the word stimuli. As is illustrated in Table 3, none of these characteristics was significantly correlated with NOF, but several were correlated with each other. Second, where two predictors were correlated, we used only the predictor that was more strongly related to NOF, in order to avoid multicollinearity among predictor variables in the regres- sion analyses. As a result, we used word frequency, subjective familiarity, word length, and NOF as predictors in our regression analyses (but not number of syllables, number of meanings, or $N$, because these were significantly correlated with word length). Using these four predictors, we conducted two stepwise regression analyses, in which the criterion variables were response latencies and response errors in Experiment 1A. Summaries of the regression analyses are presented in Table 4. Importantly, after each of the other three predictors had been entered into the regression equation, there was a significant, unique relationship between NOF and latencies and between NOF and errors. ${ }^{2}$ These results indicate that, despite potential confounds in our stimulus set, there was a unique effect of NOF in this experiment.

In Experiment 1A, the participants could more easily make lexical decisions for high-NOF words than for lowNOF words. According to the feedback activation account, this advantage was due to the additional semantic activation created by high-NOF words. This additional activation provided stronger feedback to the orthographic representation for the word presented, enhancing the activation of its orthographic units and speeding responding. In order to examine this NOF effect further, we used pseudohomophones as foils in Experiment 1B. As has been noted, according to the feedback activation account, pseudohomophone foils make lexical decisions more difficult because they require participants to set a higher criterion for orthographic activation. This leads to longer response times for both words and foils and increases the opportunity for feedback activation to affect responding. Thus, if the NOF effect is due to feedback activation from semantics to orthography, the effect should be larger in Experiment 1B.

Table 2

Mean Response Times (RTs, in Milliseconds) and Error Values (Percentages) for Word Stimuli as a Function of Number-of-Features (NOF) Condition

\begin{tabular}{|c|c|c|c|c|}
\hline \multirow[b]{2}{*}{ Experiment } & \multicolumn{2}{|c|}{ Low-NOF Words } & \multicolumn{2}{|c|}{ High-NOF Words } \\
\hline & RT & $\%$ & RT & $\%$ \\
\hline 1A (LDT with pseudoword foils) & 541 & 5.0 & 525 & 2.9 \\
\hline 1B (LDT with pseudohomophone foils) & 590 & 5.3 & 555 & 3.0 \\
\hline $1 \mathrm{C}$ (naming task) & 555 & 1.4 & 525 & 0.3 \\
\hline
\end{tabular}

Note-LDT, lexical decision task. 
Table 3

Correlations Between Characteristics for Word Stimuli $(n=50)$

\begin{tabular}{lrrrrrrr}
\hline \multicolumn{1}{c}{ Characteristic } & 1 & 2 & 3 & 4 & 5 & 6 & 7 \\
\hline 1. Number of features & \multicolumn{1}{c}{-} & & & & & & \\
2. Word length & -.22 & - & & & & \\
3. Kučera and Francis (1967) frequency & .21 & -.26 & - & & & \\
4. Subjective familiarity & .02 & -.10 & .12 & - & & \\
5. Number of syllables & -.18 & $.71^{* * *}$ & $-.37^{* *}$ & -.27 & - & \\
6. Number of meanings & -.09 & $-.38^{* *}$ & .15 & .24 & $-.46^{* * *}$ & - & \\
7. Orthographic neighborhood size & .11 & $-.62^{* * *}$ & .27 & .23 & $-.66^{* * *}$ & $.56^{* * *}$ & - \\
\hline
\end{tabular}

$* * p<.01 . \quad * * * p<.001$.

\section{Experiment 1B}

In this experiment, a trial was considered an error and was excluded from the latency analysis if the response time was longer than $2,000 \mathrm{msec}$ or shorter than $250 \mathrm{msec}$ (fewer than $1 \%$ of the trials) or if participants made an incorrect response (5.2\% of the trials). For word responses, mean latencies and mean error percentages are presented in Table 2. For nonword responses, the mean latency was $650 \mathrm{msec}$, and the mean error percentage was $6.2 \%$.

As in Experiment 1A, we first examined NOF effects in Experiment 1B with two stepwise regression analyses, using the same predictor variables. Here, the criterion variables were response latencies and response errors. Summaries of the regression analyses are presented in Table 4. Importantly, after each of the other three predictors had been entered into the regression equation, there was a significant, unique relationship between NOF and latencies in Experiment 1B.

On the basis of the feedback account, it was expected that the NOF effect in Experiment 1B (with pseudohomophone foils) would be larger than that in Experiment 1A (with pseudoword foils). One way to examine this issue statistically would be to compare the beta weights for $\mathrm{NOF}$ from the regression analyses in the two experiments, with the expectation being that the beta weight would be larger in Experiment 1B than in Experiment 1A. The problem with this analysis is that it assumes that the experiments are independent, which they are not, owing to the fact that they involved the same word stimuli. As an alternative, we carried out planned comparisons contrasting NOF effect sizes across the two experiments. The results showed that the NOF effect in Experiment 1B was significantly larger

Table 4

Summary of Stepwise Regression Analyses in Experiments 1A, 1B, and 1C

\begin{tabular}{|c|c|c|c|c|c|}
\hline Criterion Variable & Step & Predictor Variables & $R^{2}$ & $\Delta R^{2}$ & $\Delta F$ \\
\hline \multicolumn{6}{|c|}{ Experiment 1A (LDT With Pseudoword Foils) } \\
\hline \multirow[t]{4}{*}{ Response time } & 1 & Kučera and Francis frequency & .13 & .13 & $7.13^{* *}$ \\
\hline & 2 & subjective familiarity & .34 & .21 & $14.44 * * *$ \\
\hline & 3 & word length & .34 & .00 & 0.00 \\
\hline & 4 & number of features & .44 & .10 & $7.82 * *$ \\
\hline \multirow[t]{4}{*}{ Errors } & 1 & Kučera and Francis frequency & .02 & .02 & 1.09 \\
\hline & 2 & subjective familiarity & .13 & .11 & $6.22 *$ \\
\hline & 3 & word length & .21 & .08 & $4.95 *$ \\
\hline & 4 & number of features & .29 & .08 & $4.79 *$ \\
\hline \multicolumn{6}{|c|}{ Experiment 1B (LDT With Pseudohomophone Foils) } \\
\hline \multirow[t]{4}{*}{ Response time } & 1 & Kučera and Francis frequency & .16 & .16 & $9.10 * *$ \\
\hline & 2 & subjective familiarity & .38 & .22 & $16.67 * * *$ \\
\hline & 3 & word length & .44 & .06 & $4.68 *$ \\
\hline & 4 & number of features & .50 & .06 & $5.42 *$ \\
\hline \multirow[t]{5}{*}{ Errors } & 1 & Kučera and Francis frequency & .08 & .08 & $3.98 *$ \\
\hline & 2 & subjective familiarity & .27 & .19 & $12.02 * * *$ \\
\hline & 3 & word length & .30 & .03 & 1.66 \\
\hline & 4 & number of features & .34 & .04 & 2.52 \\
\hline & & Experiment 1C (Naming Task) & & & \\
\hline \multirow[t]{4}{*}{ Response time } & 1 & Kučera and Francis frequency & .03 & .03 & 1.57 \\
\hline & 2 & subjective familiarity & .12 & .09 & $4.74 *$ \\
\hline & 3 & word length & .20 & .08 & $4.36^{*}$ \\
\hline & 4 & number of features & .27 & .07 & $4.15^{*}$ \\
\hline \multirow[t]{4}{*}{ Errors } & 1 & Kučera and Francis frequency & .06 & .06 & 3.36 \\
\hline & 2 & subjective familiarity & .13 & .07 & $4.03 *$ \\
\hline & 3 & word length & .13 & .00 & 0.06 \\
\hline & 4 & number of features & .13 & .00 & 0.09 \\
\hline
\end{tabular}

Note-LDT, lexical decision task. ${ }^{*} p<.05 . \quad * * p<.01 . \quad * * * p<.001$. 
than the NOF effect in Experiment 1A for response laten$\operatorname{cies}\left[t_{1}(76)=2.41, p<.01, S E=8.83 ; t_{2}(48)=1.55, p<\right.$ $.10, S E=11.62$; both one-tailed], although not for errors $\left(t_{1}<1 ; t_{2}<1\right)$.

Unfortunately, even this analysis is somewhat problematic. As was discussed previously, there were small, nonsignificant differences between the high- and the lowNOF items on a number of factors (e.g., word frequency, length, etc.). Thus, it is possible that the larger NOF effect in Experiment 1B could have been at least partly due to there being larger effects of these other factors.

In Experiment 1C, we tested an additional prediction of the feedback activation account: Because semantic activation also facilitates the activation of phonological units, high-NOF words should also produce faster naming latencies.

\section{Experiment 1C}

In this experiment, a trial was considered an error and was excluded from the latency analysis if the naming latency was longer than $1,500 \mathrm{msec}$ or shorter than $250 \mathrm{msec}$ (fewer than $1 \%$ of the trials) or if the participants made an incorrect response (fewer than $1 \%$ of the trials). Trials on which the participants failed to trigger the voice key were also removed from the latency and error analyses (fewer than $1 \%$ of the trials). Mean naming latencies and mean error percentages are presented in Table 2 .

As in the previous experiments, we conducted stepwise regression analyses with word length, word frequency, subjective familiarity, and NOF as predictors and naming latencies and naming errors as criterion variables. Summaries of the regression analyses are presented in Table 4 . After each of the other three predictors had been entered into the regression equation, there was a significant, unique relationship between NOF and naming latencies.

\section{GENERAL DISCUSSION}

The NOF effects reported here show the influence of a previously unexamined semantic variable on visual word recognition. In the past, effects have been reported for concreteness and imageability (e.g., Cortese et al., 1997; de Groot, 1989; James, 1975; Strain \& Herdman, 1999; Strain et al., 1995; Zevin \& Balota, 2000) and for polysemy (e.g., Borowsky \& Masson, 1996; Gottlob et al., 1999; Hino \& Lupker, 1996; Hino et al., 1998; Jastrzembski, 1981; Jastrzembski \& Stanners, 1975; Kellas et al., 1988; Lichacz et al., 1999; Millis \& Button, 1989; Pexman \& Lupker, 1999; Rubenstein et al., 1970). The NOF effects reported here, presumably, are independent of these effects, because our word stimuli were all concrete nouns and were all nonpolysemous. Thus, our results provide support for the more global claim that it is the richness of a semantic representation that facilitates word recognition, regardless of how that richness is created.

We have argued here that the NOF effects observed in our LDT and naming experiments (as well as a number of other semantic effects) support Hino and Lupker's (1996) feedback activation account. A key issue to address is to what extent other models of semantic effects-in particular, polysemy effects - could explain our NOF effects.

\section{Alternative Explanations}

Kawamoto et al. (1994) reported a successful simulation of polysemy effects in LDT, using a model in which it was assumed (1) that lexical decision performance is based mainly on activation of the orthographic units and (2) that, as a result of learning with their particular error-correction algorithm, weights for connections between orthographic units were enacted differently for polysemous and nonpolysemous words. Polysemy was captured in the model by having two different semantic patterns linked to a single orthographic pattern. This inconsistent orthographicto-semantic mapping created weaker connections between orthography and semantics. As a result, connections among orthographic units became more important in producing the appropriate orthographic activation for polysemous targets. In contrast, for nonpolysemous targets, semantic activation played a major role in producing the appropriate level of orthographic activation.

With respect to NOF effects, however, there would seem to be no reason why the number of features would affect the strength of either orthographic-to-semantic mappings or the connections among orthographic units. Neither our low- nor our high-NOF words involved any orthographicto-semantic inconsistencies. Thus, the model would have no obvious way to explain an NOF effect.

Borowsky and Masson (1996) successfully simulated their polysemy effects with a model in which it was assumed that lexical decisions are made on the basis of the "familiarity for a letter string's orthography and meaning" (p. 76). The model was a Hopfield network, and familiarity was represented by the summed energy within the orthographic and meaning modules, with this energy reflecting the extent to which the network had settled into a basin of attraction. Energy was higher for polysemous words than for nonpolysemous words, owing to proximity. That is, in the model, all the meaning-level units were initially set to +1 or -1 in a random fashion. Each unit was then updated until the network moved into a correct pattern. The distance (or the number of units to be changed) from the initial pattern to the correct pattern was probabilistically smaller when there were two correct patterns of activation (i.e., for polysemous words) than when there was only one correct pattern (i.e., for nonpolysemous words). Thus, the network moved into a basin of attraction more quickly for polysemous words than for nonpolysemous words, explaining the polysemy effect observed in LDTs.

With respect to NOF effects, regardless of how many features a word has, it has only a single correct pattern of semantic activation. Thus, words with many features would not benefit from proximity in the way that polysemous words would. Therefore, as with Kawamoto et al.'s (1994) model, this model would have no obvious way of explaining NOF effects. 
It is possible that either of these models could be modified in a way that would allow them to explain NOF effects in LDTs. In fact, by changing some processing assumptions, these effects could probably be built into the models in much the same way that polysemy effects were originally built into the models. In neither case, however, would the models provide as parsimonious an account as that provided by the feedback activation account. Furthermore, in both cases, new assumptions would be needed in order to explain NOF effects in naming. This task might be especially difficult for Borowsky and Masson's (1996) model, since it was specifically designed not to produce a polysemy effect in naming.

The results of the present experiments provide evidence that LDT and naming performance is faster for words with richer semantic representations, where richness is defined in terms of the number of semantic features activated. These effects suggest that word recognition performance would be best explained by interactive models involving both feedforward and feedback activation.

\section{REFERENCES}

Balota, D. A., Ferraro, R. F., \& Connor, L. T. (1991). On the early influence of meaning in word recognition: A review of the literature. In P. J. Schwanenflugel(Ed.), The psychologyof word meanings (pp. 187221). Hillsdale, NJ: Erlbaum.

Besner, D., \& JoOrdens, S. (1995). Wrestling with ambiguity-Further reflections: Reply to Masson and Borowsky (1995) and Rueckl (1995). Journal of Experimental Psychology: Learning, Memory, \& Cognition, 21, 515-519.

BeSner, D., \& SMith, M. C. (1992). Models of visual word recognition: When obscuring the stimulus yields a clearer view. Journal of Experimental Psychology: Learning, Memory, \& Cognition, 18, 468-482.

BorowsKy, R, \& BESNER, D. (1993). Visual word recognition: A multistage activation model. Journal of Experimental Psychology: Learning, Memory, \& Cognition, 19, 813-840.

Borowsky, R., \& Masson, M. E. J. (1996). Semantic ambiguity effects in word identification. Journal of Experimental Psychology: Learning, Memory, \& Cognition, 22, 63-85.

Cohen, J. D., MacWhinney, B., Flatt, M., \& Provost, J. (1993). PsyScope: An interactive graphic system for designing and controlling experiments in the psychology laboratory using Macintosh computers. Behavior Research Methods, Instruments, \& Computers, 25, 257-271.

Cortese, M. J., Simpson, G. B., \& Woolsey, S. (1997). Effects of association and imageability on phonological mapping. Psychonomic Bulletin \& Review, 4, 226-231.

DE GRoOT, A. M. (1989). Representational aspects of word imageability and word frequency as assessed through word association. Journal of Experimental Psychology: Learning, Memory, \& Cognition, 15, 824845.

GibBs, P., \& Van Orden, G. C. (1998). Pathway selection's utility for control of word recognition. Journal of Experimental Psychology: Human Perception \& Performance, 24, 1162-1187.

Gottlob, L. R., Goldinger, S. D., Stone, G. O., \& Van Orden, G. C. (1999). Reading homographs: Orthographic, phonologic, and semantic dynamics. Journal of Experimental Psychology: Human Perception \& Performance, 25, 561-574.

HinO, Y., \& LUPKER, S. J. (1996). Effects of polysemy in lexical decision and naming: An alternative to lexical access accounts. Journal of Experimental Psychology: Human Perception \& Performance, 22, 13311356.

Hino, Y., Lupker, S. J., \& Pexman, P. M. (2002). Ambiguity and synonymy effects in lexical decision, naming, and semantic categorization tasks: Interactions between orthography, phonology, and semantics. Journal of Experimental Psychology: Learning, Memory, \& Cognition, 28, 686-713.
Hino, Y., Lupker, S. J., Sears, C. R., \& Ogawa, T. (1998). The effects of polysemy for Japanese katakana words. Reading \& Writing: An Interdisciplinary Journal, 10, 395-424.

JAMES, C. T. (1975). The role of semantic information in lexical decisions. Journal of Experimental Psychology: Human Perception \& Performance, 1, 130-136.

JAST RZEMBSKI, J. E. (1981). Multiple meanings, number of related meanings, frequency of occurrence, and the lexicon. Cognitive Psychology, 13, 278-305.

JASTRZEMbSKi, J. E., \& StAnners, R. F. (1975). Multiple word meanings and lexical search speed. Journal of Verbal Learning \& Verbal Behavior, 14, 534-537.

JoNES, G. V. (1985). Deep dyslexia, imageability, and ease of predication. Brain \& Language, 24, 1-19.

Joordens, S., \& BESNER, D. (1994). When banking on meaning is not (yet) money in the bank: Explorations in connectionist modeling. Journal of Experimental Psychology: Learning, Memory, \& Cognition, 20, 1051-1062.

Kawamoto, A. H., Farrar, W. T., \& Kello, C. T. (1994). When two meanings are better than one: Modeling the ambiguity advantage using a recurrent distributed network. Journal of Experimental Psychology: Human Perception \& Performance, 20, 1233-1247.

KeIL, F. C. (1989). Concepts, kinds and cognitive development. Cambridge, MA: MIT Press.

Kellas, G., Ferraro,F. R., \& Simpson, G. B. (1988). Lexical ambiguity and the timecourse of attentional allocation in word recognition. Journal of Experimental Psychology: Human Perception \& Performance, 14, 601-609.

KuČERA, H., \& FrAnCIS, W. (1967). Computationalanalysis of presentday American English. Providence, RI: Brown University Press.

Lichacz, F. M., Herdman, C. M., LeFevre, J., \& Baird, B. (1999). Polysemy effects in naming. Canadian Journal of Experimental Psychology, 53, 189-193.

McRAe, K., \& Cree, G. S. (in press). Factors underlying category specific semantic deficits. In E. M. E. Forde \& G. W. Humphreys (Eds.), Category-specificity in brain and mind. East Sussex, U.K.: Psychology Press.

McRae, K., Cree, G. S., Westmacott, R., \& de Sa, V. R. (1999). Further evidence for feature correlations in semantic memory. Canadian Journal of Experimental Psychology, 53, 360-373.

McRae, K., DE SA, V. R., \& Seidenberg, M. S. (1997). On the nature and scope of featural representations of word meaning. Journal of Experimental Psychology: General, 126, 99-130.

Medin, D. L. (1989). Concepts and conceptual structure. American Psychologist, 44, 1469-1481.

Millis, M. L., \& Button, S. B. (1989). The effect of polysemy on lexical decision time: Now you see it, now you don't. Memory \& Cognition, 17, 141-147.

Pecher, D. (2001). Perception is a two-way junction: Feedback semantics in word recognition. Psychonomic Bulletin \& Review, 8, 545-551.

Pexman, P. M., \& Lupker, S. J. (1999). Ambiguity and visual word recognition: Can feedback explain both homophone and polysemy effects? Canadian Journal of Experimental Psychology, 53, 323-334.

Pexman, P. M., LupKer, S. J., \& JAREd, D. (2001). Homophone effects in lexical decision. Journal of Experimental Psychology: Learning, Memory, \& Cognition, 27, 139-156.

Piercey, C. D., \& Joordens, S. (2000). Turning an advantage into a disadvantage: Ambiguity effects in lexical decision versus reading tasks. Memory \& Cognition, 28, 657-666.

Plaut, D. C., \& Shallice, T. (1993). Deep dyslexia: A case study of connectionist neuropsychology. Cognitive Neuropsychology, 10, 377 500 .

RIPS, L. J. (1989). Similarity, typicality, and categorization. In S. Vosniadou \& A. Ortony (Eds.), Similarity and analogical reasoning (pp. 2159). Cambridge: Cambridge University Press.

Rubenstein, H., Garfield, L., \& Millikan, J. A. (1970). Homographic entries in the internal lexicon. Journal of Verbal Learning \& Verbal Behavior, 9, 487-494.

Rubenstein, H., Lewis, S. S., \& Rubenstein, M. A. (1971). Evidence for phonemic recoding in visual word recognition. Journal of Verbal Learning \& Verbal Behavior, 10, 645-657. 
RuecKL, J. G. (1995). Ambiguity and connectionist networks: Still settling into a solution-Comment on Joordens and Besner (1994). Journal of Experimental Psychology: Learning, Memory, \& Cognition, 21, 501-508.

SeidenberG, M. S., \& McClelland, J. L. (1989). A distributed, developmental model of word recognition and naming. Psychological Review, 96, 523-568.

Stolz, J. A., \& NeEly, J. H. (1995). When target degradation does and does not enhance semantic context effects in word recognition. Journal of Experimental Psychology: Learning, Memory, \& Cognition, 21, 596-611.

Stone, G. O., Vanhoy, M., \& Van Orden, G. C. (1997). Perception is a two-way street: Feedforward and feedback phonology in visual word recognition. Journal of Memory \& Language, 36, 337-359.

Stone, G. O., \& VAn Orden, G. C. (1993). Strategic control of processing in word recognition. Journal of Experimental Psychology: Human Perception \& Performance, 19, 744-774.

Strain, E., \& Herdman, C. M. (1999). Imageability effects in word naming: An individual differences analysis. Canadian Journal of Experimental Psychology, 53, 347-359.
Strain, E., Patterson, K., \& Seidenberg, M. S. (1995). Semantic effects in single-word naming. Journal of Experimental Psychology: Learning, Memory, \& Cognition, 21, 1140-1154.

VAn Orden, G. C., \& Goldinger, S. D. (1994). The interdependence of form and function in cognitive systems explains perception of printed words. Journal of Experimental Psychology: Human Perception \& Performance, 20, 1269-1291.

Zevin, J. D., \& Balota, D. A. (2000). Priming and attentional control of lexical and sublexical pathways during naming. Journal of Experimental Psychology: Learning, Memory, \& Cognition, 26, 121-135.

\section{NOTES}

1. The stimuli used in these experiments are available from the first author.

2. When additional regression analyses were conducted using all seven predictor variables, the results concerning NOF were unchanged: There was still a significant, unique effect of NOF for response latencies and errors in Experiment 1A. Similarly, for Experiments 1B and $1 \mathrm{C}$, results were unchanged when all seven predictors were used.

(Manuscript received November 2, 2000;

revision accepted for publication October 2, 2001.) 